\title{
Accountability, debilidades de las instituciones de asistencia privada en el Estado de México
}

\author{
Gloria Guadarrama Sánchez*
}

\begin{abstract}
This paper presents an initial exploration of the accountability of private welfare institutions operating in the State of Mexico. This exploration takes into account the vigilance that the State imposes over the institutio$n s$ in order to identify the relationships between regulation and strength or weakness in the institutional ensemble. We start by considering that the laxity and permissivity in regulations could operate negatively in the robustness and the continuity of the institutions. The results allow us to identify some of the current problems of accountability and their repercussions in terms of the weaknesses of the institutions.
\end{abstract}

Keywords: private welfare, accountability, institutions.

\section{Resumen}

En este texto se presenta una exploración inicial de las capacidades de rendición de cuentas de las instituciones de asistencia privada que operan en el Estado de México, a partir de la vigilancia que el Estado ejerce sobre ellas, con la intención de identificar las relaciones entre la regulación y la fortaleza o debilidad del conjunto institucional. La exploración parte de considerar que la laxitud y permisividad en la regulación pueden operar negativamente en la solidez y la continuidad de las instituciones. Los resultados permiten identificar algunos de los problemas que actualmente se presentan para una adecuada rendición de cuentas y sus repercusiones en términos de la debilidad de las instituciones.

Palabras clave: asistencia privada, accountability, rendición de cuentas, instituciones.

* El Colegio Mexiquense, A.c. Correo-e: gguadarr@cmq.edu.mx. 


\section{Introducción $^{1}$}

En México existen pocos estudios orientados a examinar las formas de organización y administración de las organizaciones civiles y de las instituciones asistenciales privadas, así como sus implicaciones para la política social. ${ }^{2}$ Todavía en menor proporción se cuenta con estudios sobre los mecanismos de rendición de cuentas que utilizan ese tipo de asociaciones. La falta de una visión objetiva sobre esos procesos se traduce tanto en el entusiasmo desmedido como en el cuestionamiento infundado sobre la contribución de esos grupos al bienestar de la sociedad. En el caso de nuestro país, a partir de los años finales del siglo xx se ha intensificado el debate sobre si las asociaciones asistenciales que implican participación privada y voluntarismo deben o no rendir cuentas sobre su desempeño y sobre los recursos financieros que manejan. En el examen que aquí se realiza sobre esas posiciones se toma en cuenta que las normas formales relativas a los procesos de accountability son determinantes en las formas que asume la organización institucional, y se considera que tienen una repercusión importante en el incremento o disminución de la participación social privada.

Este análisis sobre la rendición de cuentas de las instituciones asistenciales privadas tiene el propósito de indagar si las insuficiencias que actualmente presentan las instituciones mexicanas de asistencia privada en ese rubro se traducen en debilidades que afectan su permanencia y su consolidación institucional, al tiempo que obstaculizan el que puedan desempeñar un rol de mayor relevancia en la asistencia social para la población hacia la cual orientan sus servicios.

${ }^{1}$ Este artículo es resultado de una ponencia que se presentó en el v Seminario Anual de Investigación sobre el Tercer Sector en México, efectuado en la Universidad Iberoamericana en octubre de 2005; una versión de la ponencia aparecerá próximamente en un libro publicado por el Instituto Federal de Acceso a la Información Pública (IFAI) y coordinado por Alberto Hernández Baqueiro, Transparencia, rendición de cuentas y construcción de confianza en la sociedad y el estado mexicanos, México, IFAI, 2006.

${ }^{2}$ No se cuenta en nuestro país con programas de estudio orientados a examinar la administración de las organizaciones civiles no lucrativas, pero algunas instituciones educativas y centros de investigación han incursionado en ese rubro; entre ellos se cuentan los siguientes: el Centro Mexicano para la Filantropía, el Programa Interdisciplinario de Estudios del Tercer Sector de El Colegio Mexiquense, la Universidad Autónoma Metropolitana y el Instituto Tecnológico Autónomo de México. Se puede afirmar, no obstante, que los estudios sobre rendición de cuentas de las organizaciones civiles son escasos. En otros países se tienen programas afines: The Center for Civil Society, de la London School of Economics and Political Science; The Mandel Center for Nonprofits Organizations, de la Case Western Reserve University en Ohio, y The Program on Nonprofit Organizations, de la Yale University. 
Con esa intención se examinan las capacidades institucionales de rendición de cuentas del conjunto de instituciones de asistencia privada (IAP) que operaron en el Estado de México durante el periodo 2000-2002, a partir de la vigilancia que el gobierno ejerce sobre ellas, así como las relaciones entre la regulación que ejercen las normas formales y la fortaleza o la debilidad del conjunto institucional. ${ }^{3}$ La base para analizar esas relaciones es la supervisión que realiza la Junta de Asistencia Privada del Estado de México (JAPEM), como el organismo responsable de autorizar y vigilar el establecimiento y la operación de las instituciones asistenciales. El análisis se realiza mediante el seguimiento de los reportes documentados de las visitas de supervisión a las 171 instituciones que operaron en la entidad durante el periodo de estudio. ${ }^{4}$

\section{Los presupuestos de la rendición de cuentas}

Las instituciones de asistencia privada en México se organizan en torno a objetivos sociales, que son generalmente enunciados en términos de protección a los pobres y desamparados; es decir, asumen como su razón de ser el cumplimiento de una misión social, la cual les confiere una justificación tácita ante la sociedad. ${ }^{5}$ En la ejecución de esa misión, las instituciones generan diversos tipos de servicios, los que tienen o producen diversos tipos de valor económico y social. En ese sentido, si bien las instituciones se definen a sí mismas como no lucrativas, llevando implícito que su tarea no está destinada a la obtención de lucro o ganancias personales, las condiciones de rendición de cuentas sobre los recursos que utilizan son diversas y los límites de su desempeño entre el interés público y el privado son borrosos, lo

\footnotetext{
${ }^{3}$ El análisis no tiene la intención de caracterizar la rendición de cuentas en el contexto nacional. La selección del Estado de México como unidad de análisis es arbitraria; sin embargo, las características demográficas y económicas de esa entidad, así como las dimensiones de su sistema de asistencia privada, le confieren alguna representatividad en el panorama de las instituciones de asistencia privada en otras entidades federativas.

${ }^{4}$ La JAPEM realizó visitas de supervisión a 122 del total de las instituciones registradas en el periodo de estudio, lo que corresponde a $71.3 \%$ del conjunto institucional. De ese universo, $60 \%$ fueron visitadas en más de una ocasión.

${ }^{5}$ El examen de los fines del conjunto de instituciones al que se hace referencia revela que éstas orientan su acción por fines genéricos expresados en términos de: "brindar ayuda al prójimo", "procurar el bien de los demás" y "aliviar la pobreza"; enarbolando como principios la generosidad y el carácter no lucrativo de sus acciones. Se aprecia que esos propósitos, vertidos en sus estatutos constitutivos, forman parte del código general compartido que legitima su función ante la sociedad (Guadarrama, 2005).
} 
que pone en tela de juicio las bondades de su participación como agentes generadores de bienestar social.

En ese contexto, en las últimas dos décadas se registraron en el país cambios en las relaciones entre el Estado y las instituciones de tipo asistencial privado, advirtiéndose cierta presión del gobierno para el control sobre las facilidades fiscales que se les otorgan a esas instituciones y para intensificar la rendición de cuentas sobre los recursos que manejan. Frente a esas medidas, las instituciones realizaron una amplia movilización en favor de lograr autonomía y mayores incentivos, enarbolando los beneficios sociales de la labor que realizan; por lo que toca a la rendición de cuentas, se ha argumentado que no pueden ser tasadas con la misma medida que las empresas privadas de tipo lucrativo, demandando incentivos, autonomía y flexibilidad para dar cuenta de su operación y resultados.

La capacidad de rendir cuentas - accountability- es generalmente interpretada como el conjunto de activos que permiten a las instituciones asumir responsabilidad por sus acciones y reportar ante autoridades reconocidas. ${ }^{6}$ Esa capacidad es la que posibilita establecer niveles de confianza en que las instituciones cumplan con sus objetivos sociales. En el caso de las instituciones asistenciales privadas, la capacidad de rendir cuentas puede traducirse en un factor determinante para la fortaleza y consolidación de las instituciones, puesto que su operación depende, en buena medida, de la confianza de donadores y voluntarios en el buen destino de sus contribuciones y en un adecuado desempeño institucional.

La capacidad de rendir cuentas incluye, además de la confian$\mathrm{za}$, la suficiencia institucional para enfrentar demandas, deudas y obligaciones, y en ese sentido tiene que ver con la sostenibilidad y fortaleza de las instituciones. En el caso de instituciones especialmente dedicadas a la atención de poblaciones vulnerables, esa atención está también vinculada a la posibilidad de tomar decisiones éticas que consideren el manejo adecuado de los

${ }^{6}$ Michel S. Martell (2005) señala la inexistencia en el idioma español de un término equivalente a accountability, puesto que el término afín "responsabilidad" se asocia más frecuentemente con el sentido de obligación y no con la "conciencia de las implicaciones de los actos". Puntualiza que el término accountability se conoce y emplea con un sentido más amplio en el habla inglesa, como la responsabilidad impuesta o asumida por una persona o un grupo para la efectividad o éxito de determinado programa, actividad y/o proyecto, en cuanto a los resultados alcanzados, lo cual implica un requerimiento implícito o explícito para aceptar responsabilidad por el desempeño, progreso y logro. Esta observación es importante porque permite incluir en el concepto la responsabilidad integral por los programas de interés público. 
recursos en favor de sus beneficiarios. De ese modo, la rendición de cuentas se asocia con las potencialidades de consolidación institucional y puede constituirse en un punto determinante para la permanencia y la continuidad de las instituciones.

La relevancia social de las instituciones se encuentra sustancialmente asentada en la correspondencia entre sus fines y los medios disponibles para alcanzarlos, en su relación con las necesidades que se pretenden atender, y en la medida en la que puedan responder a las demandas sociales. Las instituciones adquieren así connotaciones de fortaleza o de fragilidad implícitas en sus potencialidades para ser estables, sostenibles y adecuadas para cumplir con su objeto social.

Del mismo modo se puede afirmar que la rendición de cuentas incide en la percepción social sobre el mejor desempeño institucional, puesto que permite clarificar el logro de los objetivos, los que justifican a su vez las acciones emprendidas, asegurando que los recursos son bien empleados; ya que, en situación contraria, los donadores pueden cancelar sus aportaciones y el gobierno puede retirar los subsidios e incluso clausurar las instituciones. La consideración derivada de esos planteamientos es el supuesto de que las deficiencias en los procesos de accountability se traducen en condiciones de debilidad organizacional que conducen al fracaso o a la extinción de las instituciones.

Es pertinente aclarar que la obligación de rendir cuentas, como otras obligaciones legales y morales, es generalmente atribuida a las personas, no a las instituciones, y que algunas posiciones analíticas sostienen que las obligaciones no pueden ser referidas al ámbito institucional. Sin embargo, en este análisis se sostiene que la rendición de cuentas es un atributo de fortaleza o debilidad del conjunto institucional, sobre la base de considerar, como propone Russell Hardin (2003: 163), que las instituciones tienen capacidades que trascienden las de los individuos y que la conducta de quienes las constituyen es construida socialmente, con la influencia del contexto institucional. De ese modo nos explica que la moralidad de una institución como un todo está razonablemente bien definida por su propósito y sus efectos. ${ }^{7}$

Otra de las razones para referir la obligación de rendir cuentas al ámbito institucional se encuentra en la argumentación de John Ferejohn, referida a que la accountability es una propiedad

${ }^{7}$ El análisis de la rendición de cuentas se asume desde la posición de Hardin, en el sentido de que resulta una perversión colocar a las instituciones fuera del discurso moral, ya que es imposible lograr los objetivos morales sin ellas (Hardin, 2003). 
de las estructuras institucionales, mientras que la responsabilidad personal es una consecuencia de la interacción dentro de dichas estructuras. Es decir, la responsabilidad personal es una medida del grado de accountability que la estructura institucional permite (Ferejohn, 1999: 131). ${ }^{8}$ En ese sentido se advierte que la legislación mexicana marca responsabilidades institucionales para la rendición de cuentas y previene sanciones, no solamente personales sino también institucionales, para el manejo indebido de recursos financieros y bienes materiales, así como para la desviación de éstos de los objetivos sociales autorizados. ${ }^{9}$

\section{Los componentes de la rendición de cuentas}

Como lo advierte John D. Clark (2003), en lo que concierne a la transparencia y la rendición de cuentas para las organizaciones civiles pueden identificarse tres componentes: para qué, a quién, y cómo.

- El primer componente, para qué, considera que la organización y sus recursos sirvan a los fines propuestos (interés en los pobres, en el ambiente, en el beneficio de la comunidad, etc.), asumiendo, implícitamente, que la información respecto a los problemas y a la ayuda para resolverlos sea precisa, mediante vías sostenibles, que no sean solamente acciones de corto plazo y que la asociación y su constitución sean genuinas.

- En el caso del segundo componente, a quién, se consideran el reconocimiento y la aceptación social de la institución, implicando la existencia de un núcleo de legitimidad representado por un cuerpo de autoridades o representantes sociales reconocidos. En el caso de las instituciones de asistencia privada,

\footnotetext{
${ }^{8}$ Ferejohn aplica esta argumentación en su análisis sobre una teoría de la accountability política, manejada como una concepción endógena de accountability, en la que se consideran las condiciones en las cuales los agentes políticos pueden hacerse a sí mismos más o menos "accountables" al escrutinio público (Ferejohn, 1999).

${ }^{9}$ La consideración se sustenta en argumentos discutidos en la Suprema Corte de la Nación, en función de la resolución sobre la controversia derivada de la "Acción de inconstitucionalidad 1/99. Ley de Instituciones de Asistencia Privada del Distrito Federal", que consideró a la asistencia social como un servicio público; es decir, como una actividad directa del Estado que es autorizada o delegada a los particulares, lo que significa que pueda ser ejecutada por las organizaciones civiles privadas, las que colaboran con el Estado, reservándose éste el control y teniendo facultades para limitar los derechos de los particulares. La referencia a la asistencia como un servicio público implica, asimismo, las facultades del Estado para determinar cómo puede integrarse el patrimonio de los sujetos que realizan las acciones de servicio público y cuáles reglas les serán aplicables a sus cuestiones patrimoniales (Gudiño, 1999).
} 
este punto implica la rendición de cuentas ante directivos, cuerpos colegiados, asociados, patronatos, juntas directivas y donantes, así como ante el gobierno y la sociedad.

- El tercer componente, cómo, involucra las formas como las instituciones pueden hacer un uso adecuado y correcto de sus recursos; también lleva implícita una cierta expertise (experiencia, conocimiento del asunto) en la atención del problema, y en esa especialización está implícito un nivel en el cual las instituciones puedan ser abiertas al escrutinio público. El punto, para el caso particular de las instituciones asistenciales, también tiene que ver con la percepción de que las instituciones filantrópicas deben ser, en lo posible, instituciones virtuosas.

Andreas Schedler (1999: 14-16) señala también algunos de los elementos conceptuales que se involucran en la idea de rendición de cuentas; nos explica que el concepto de accountability contiene dos nociones básicas: la primera se refiere a responder por las acciones y decisiones, así como a la obligación de informar sobre ellas y explicarlas; y la segunda, que corresponde a la noción coercitiva, implica la capacidad de imponer sanciones a las desviaciones de los presupuestos establecidos.

Por otra parte, de acuerdo con algunos principios planteados por las perspectivas neoinstitucionalistas, la rendición de cuentas es una precondición de la eficiencia de las instituciones, puesto que las reglas para que éstas sean efectivas deben acompañarse de mecanismos de monitoreo y de castigo que prevengan su eventual violación. En las instituciones privadas que brindan servicios asistenciales, esas prescripciones implican la obligación por parte de quienes fundan y administran las instituciones de dar cuenta de su manejo, mientras que exigir la rendición de cuentas demanda la existencia de una autoridad reconocida que pueda prevenir y, en su caso, sancionar las desviaciones, papel que hasta el momento corresponde a la Junta de Asistencia Privada. Se presupone asimismo la existencia de normas que articulan la organización institucional.

Con relación a los tipos de accountability, es posible distinguir entre aspectos referidos a la accountability política, que capturan la pertinencia de las políticas institucionales u organizacionales y de los procesos de su construcción a la vista del trazo de objetivos propios; la accountability administrativa, que involucra enjuiciar la corrección y la oportunidad de los procedi- 
mientos; la accountability de la profesionalidad, que vigila los estándares de profesionalismo de las instituciones; la accountability financiera, que tiene que ver con sujetar los recursos públicos a normas de austeridad, eficiencia y pertinencia, y la accountability legal, que vigila la observancia a las normas formales con base en los criterios legales establecidos. Estos ámbitos o formas de $a c$ countability son mencionados por Schedler como elementos que se integran en el concepto de rendición de cuentas y que son susceptibles de ser subdivididos en otros muchos, al igual que pueden variar de acuerdo con los ámbitos de su aplicación.

Dadas las limitaciones del análisis que aquí se presenta, la exploración de las nociones y de los componentes toca solamente algunos de esos aspectos, particularmente los asociados con la vigilancia que ejerce el gobierno por medio de la JAPEM sobre las IAP, situación que deriva de la inexistencia de información sobre rendición de cuentas a otros actores políticos y sociales que se involucran en la asistencia. La indagación se orienta, preferentemente, hacia las declaraciones sobre el logro de los fines genéricos y el manejo de bienes y recursos económicos, debido a que las instituciones informan escasamente sobre otras características de su desempeño, sobre sus resultados, y sobre el valor social de sus aportaciones, lo que no permite aproximarse a la rendición de cuentas en esos rubros.

La rendición de cuentas como proceso implica dos momentos: el control ex ante, que permite determinar el estado inicial de las instituciones, y la rendición de cuentas ex post, que posibilita aprehender su manejo y sus resultados en relación con las premisas aceptadas para su funcionamiento. ${ }^{10}$ En este estudio se examinan los dos momentos con las particularidades que tiene la rendición de cuentas de las IAP en el esquema de vigilancia establecido en el Estado de México.

\section{Accountability e instituciones de asistencia privada en México}

La vigilancia y rendición de cuentas para las instituciones asistenciales privadas en México se estableció formalmente con la constitución legal de la Junta de Beneficencia Privada -considerada en la Ley de Beneficencia Privada, decretada por el presidente Porfirio Díaz el 7 de noviembre de 1889-, entre cuyas atri-

${ }^{10}$ La concepción de la rendición de cuentas como un mecanismo de control ex ante y ex post proviene de estudios sobre el tema realizados por Jon Elster (1999). 
buciones se encontró la promoción y vigilancia de los establecimientos fundados por particulares. En función de ese ordenamiento, a las instituciones de beneficencia creadas y administradas por particulares con fines caritativos les fue reconocida personalidad jurídica.

La ley establecía para los patronos de las instituciones la obligación de remitir a la Junta de Beneficencia Privada un corte de caja anual sobre sus movimientos y desempeño; puntualizaba que las instituciones tenían la obligación de justificar, siempre que para ello fueren requeridas, el exacto cumplimiento del objeto de la institución y la pureza en el manejo de los fondos. ${ }^{11}$ La Junta, como autoridad establecida para tomar cuentas del buen funcionamiento de las instituciones, tenía funciones coercitivas concebidas como funciones de vigilancia que debían impedir: "la distracción o dilapidación de los fondos, los fraudes de los administradores o patronos o la inejecución de la voluntad del fundador". ${ }^{12}$ En el ejercicio de sus funciones, la Junta podía fincar responsabilidades civiles y penales a quienes faltaren a sus responsabilidades como administradores o patronos de las instituciones.

En la construcción histórica de las responsabilidades institucionales de rendición de cuentas debe asimismo tomarse en cuenta que ya en las leyes respectivas, modificadas por el mismo presidente Díaz en 1904, se consideraban las acciones de beneficencia ejecutadas con fondos particulares como las que tenían un objeto de utilidad pública, dándoseles así una connotación de bienes públicos: "No se reputan actos de beneficencia los que no tienen un objeto de utilidad pública ó son contrarios a la ley, a la moral ó a las buenas costumbres". ${ }^{13}$ Esa noción, implícita en la constitución legítima de la intervención de los particulares en la asistencia, es de la mayor trascendencia para la rendición de cuentas, ya que sobre esa base se justifica la intervención y la vigilancia del Estado sobre las instituciones, erigiéndose la Junta como autoridad legal ante la cual dar cuenta del manejo institucional y, sobre todo, del empleo de los recursos. Simultáneamente se constituyó un sistema de incentivos fiscales y subsidios para alentar, regular y controlar la participación de los agentes privados en las acciones asistenciales.

${ }^{11}$ Artículos $6^{\circ}, 40^{\circ}, 41^{\circ}$ y $47^{\circ}$ de la Ley de la Beneficencia Privada para el Distrito Federal y Territorios, publicada en el Diario Oficial del Supremo Gobierno de los Estados Unidos Mexicanos, el 7 de noviembre de 1899.

${ }^{12}$ Artículos $45^{\circ}$ y $54^{\circ}$.

${ }^{13}$ Artículo $1^{\circ}$ de la Ley de Beneficencia Privada para el Distrito y Territorios Federales, Diario Oficial de los Estados Unidos Mexicanos, 24 de agosto de 1904. 
Tales prescripciones operaron con algunas modificaciones y se aplicaron con notable flexibilidad por parte de las autoridades gubernamentales hasta principios de los años treinta, cuando se plantearon mayores exigencias para el control de las instituciones sobre la base de considerar que la beneficencia debía organizarse como un servicio público, para lo cual se juzgaba indispensable establecer controles efectivos a la administración. ${ }^{14}$ El rigor en la regulación de la asistencia privada durante esa etapa, conocida como el Cardenismo, se concretó en una supervisión exhaustiva de las instituciones privadas y estuvo inserto en el proyecto más amplio del Estado como responsable de asegurar el bienestar de la población, contexto en el cual la filantropía perdía relevancia. ${ }^{15}$

Posteriormente, durante los años de 1940 a 1958 se favoreció de nueva cuenta una más amplia intervención de los particulares en la asistencia, flexibilizándose la regulación y la supervisión sobre la rendición de cuentas en el manejo de sus fondos y capitales. ${ }^{16}$ La rendición de cuentas comprendía informar a la Junta de los programas de trabajo y llevar libros de contabilidad conforme a presupuestos establecidos; la vigilancia incluía, además de lo ya indicado, la comprobación del cumplimiento de normas técnicas de higiene y salubridad en los establecimientos, fijándose sanciones al mal funcionamiento de las mismas. Preceptos que se mantuvieron con algunos cambios hasta 1989 , cuando se empezaron a generar los marcos normativos que regulan actualmente la rendición de cuentas en las instituciones asistenciales privadas. ${ }^{17}$

\footnotetext{
${ }^{14}$ Exposición de motivos del presidente Abelardo L. Rodríguez, para expedir una nueva Ley de Beneficencia Privada para el Distrito y Territorios Federales. Diario Oficial del Gobierno Constitucional de los Estados Unidos Mexicanos, 20 de diciembre de 1932.

${ }^{15} \mathrm{El}$ control exhaustivo se infiere de innumerables prescripciones establecidas en el articulado de la legislación de 1933, las que fijan criterios para la rendición de informes contables y financieros; dichas precisiones consideran obligaciones específicas para los inspectores y detallan las responsabilidades en que se incurría por incumplimiento de los preceptos marcados. Ley de Beneficencia Privada para el Distrito y Territorios Federales, Diario Oficial del Gobierno Constitucional de los Estados Unidos Mexicanos, 31 de mayo de 1933.

${ }^{16}$ La flexibilidad se infiere no solamente de la reanudación de incentivos fiscales, sino también del hecho de que la mayoría de las instituciones que operaban podían hacerlo sin registro y prácticamente sin supervisión (Guadarrama, 2005).

${ }^{17}$ En el caso de México, hasta 1989 las asociaciones civiles estuvieron consideradas en un régimen fiscal que las ubicaba en la fracción vi del Artículo 70 de la Ley del Impuesto sobre la Renta, lo cual permitía considerarlas como personas morales no lucrativas. Las modificaciones fiscales efectuadas en ese año cambiaron esa situación, restringiendo la aplicabilidad de las exenciones impositivas consideradas anteriormente (Reygadas, 1998).
} 
Desde el comienzo de los años noventa fue posible observar que los arreglos que mantenían integradas las líneas principales del modelo de rendición de cuentas de las IAP mexicanas, se habían fracturado en varios puntos: el primero y más importante fue la reestructuración del esquema de incentivos fiscales y subsidios; el segundo, la modificación de las prescripciones en la legislación, las cuales limitaron la discrecionalidad que ejercía el gobierno en la asignación de apoyos y subsidios a las organizaciones e instituciones civiles, a la par que obligaron a éstas a la rendición de cuentas; el tercer punto crítico fue la falta de adecuación del patrón de rendición de cuentas a la diversificación de los servicios y a nuevas necesidades institucionales, sobre todo porque no se consideraron mecanismos que permitieran tomar en cuenta las repercusiones sociales de las tareas asistenciales.

A partir de esa ruptura comenzó a registrarse en el país un cambio en las relaciones entre el Estado y las instituciones privadas que se dedican a la asistencia. Algunos aspectos de ese cambio pueden resumirse en el reconocimiento de que tanto el gobierno como la sociedad consideran necesaria e intrínsecamente buena la labor de esas instituciones, por lo que les conceden reconocimiento legal, incentivos y estímulos traducidos como prerrogativas fiscales. ${ }^{18}$ Parte de ese movimiento de reacomodo fue la reactivación de la discusión sobre la adecuación normativa de la rendición de cuentas y sobre los mecanismos empleados para valorar su desempeño y resultados.

En el caso del Estado de México, los cambios registrados entre 1993 y 2001 en las prescripciones que legitiman y ordenan la asistencia privada permiten la inserción en el orden rector de la sociedad, de individuos y grupos de particulares que, para realizar actos de asistencia y constituir instituciones para esos propósitos, son sujetos de derechos y obligaciones. De manera simultánea, las normas recientemente instituidas (2001 y 2004) establecen la previsión de la vigilancia de dichos actos, para evitar el mal uso de los atributos y prerrogativas mencionados. ${ }^{19}$ Los rasgos de la regulación conducen a pensar que las normas establecen que las instituciones sean imputables y que deban rendir cuentas de su des-

${ }^{18}$ El reconocimiento de las instituciones como personas morales implica la aptitud para actuar en el campo del derecho, en virtud de un conjunto de atributos regulados por las leyes; entre esos atributos se encuentran: el nombre, el domicilio, la nacionalidad, la capacidad para cumplir con su objeto social, y su patrimonio (Domínguez y Reséndiz, 2001: 27).

${ }^{19}$ Ley de Instituciones de Asistencia Privada del Estado de México (2001) y Ley de Asistencia Social (2004). 
empeño y probidad en el uso de sus recursos. La imputabilidad es entendida aquí como el estado en el cual las instituciones son responsables por el propio desempeño y por la confianza que se deposita en ellas. ${ }^{20}$ La condición de imputabilidad tiene costos y beneficios para las instituciones: entre los beneficios se identifica el de prevenir y desalentar conductas indebidas y desviaciones respecto a los fines institucionales; entre los costos están las sanciones que previene la legislación y la pérdida de confianza. ${ }^{21}$ El órgano ex profeso que supervisa el funcionamiento institucional es la Junta de Asistencia Privada.

Debe notarse que si bien la instancia de autoridad ante la cual rendir cuentas, en este caso la Junta de Asistencia Privada, no ha cambiado desde su constitución formal en 1899, la composición interna del organismo sí se modificó en el transcurso del siglo xx, porque la Junta fue, paulatinamente, integrando en su estructura orgánica a una mayor proporción de representantes de las instituciones. ${ }^{22}$ Esa transformación es importante en razón de incluir en la rendición de cuentas los intereses y presupuestos institucionales.

\section{El modelo de rendición de cuentas}

Las instituciones de asistencia privada se distinguen de las públicas principalmente porque destinan fondos privados al desarrollo de su tarea asistencial. En función de esta característica, la capacidad de rendir cuentas resulta fundamental para su operación, tanto por el hecho de que se cumpla la voluntad de asociados y fundadores, en términos de administrar recursos destinados a fines predeterminados de asistencia, como por la circunstancia de que parte de su operación se sustenta con recursos externos, proce-

${ }^{20}$ La legislación nacional en la materia previene que las instituciones asistenciales públicas y privadas ajusten su funcionamiento a normas oficiales, mediante el establecimiento de terminología, directrices, atributos, especificaciones y características aplicables a personas, procesos y servicios (Artículos $63^{\circ}$ y $64^{\circ}$ de la Ley de Asistencia Social, 2004). En el mismo sentido se puede interpretar el otorgamiento de personalidad jurídica a las instituciones, condición que las convierte en sujetos de derechos y obligaciones. En el ámbito estatal, la Ley de Instituciones de Asistencia Privada (2001) vigente incluye numerosas precisiones sobre las responsabilidades de rendición de cuentas de las IAP.

${ }^{21} \mathrm{La}$ interpretación está asociada con algunos de los significados de accountability en la lengua inglesa: to account, to consider, to credit o impute to (The Living Webster Dictionary of the English Language, 1981).

22 En el caso del Estado de México, la JAPEM se constituye actualmente por un presidente, cinco vocales representantes del sector público estatal y seis vocales designados por las instituciones, con lo cual se considera una composición paritaria del organismo fiscalizador. 
dentes de donativos realizados con propósitos de ayuda y de atención a personas y a problemas sociales determinados.

Las bases para justificar la intervención del Estado y sus atribuciones en la vigilancia institucional se arraigan en la noción de que los servicios que esas instituciones prestan son de interés público. $^{23}$ Se distinguen tres momentos o actos principales de intervención: la autorización de la institución, su vigilancia y su extinción (Junta de Asistencia Privada, 1950: XIII). ${ }^{24}$ El primer momento corresponde a la acción ex ante, y los dos últimos a la acción ex post.

El momento de autorización de la institución condensa un conjunto de procedimientos vinculados con la constitución legal de ésta y con su reconocimiento como personas morales. Corresponde a la Junta otorgar o no el reconocimiento formal que lleva implícita la aceptación del objeto social, de los principios estatutarios y de las bases esenciales para la operación de la institución.

El segundo acto de la intervención estatal consiste en la vigilancia del ejercicio institucional; este acto se infiere dirigido por la preservación del interés público y por la intención de asegurar que se cumpla la voluntad de los fundadores, se ejerzan adecuadamente las prerrogativas y se cuiden los bienes, aspectos que, en lo general, se integran en el adecuado cumplimiento de los fines asistenciales.

Finalmente, la intervención del Estado en la extinción de las instituciones es vista desde una perspectiva que hace a los beneficiarios los titulares de los bienes, pues al ser éstos de carácter privado, no puede el Estado, en ningún caso, apropiarse de ellos. En esa virtud, al extinguirse una institución corresponde al Estado intervenir para cuidar que el patrimonio remanente continúe asociado con propósitos asistenciales (Junta de Asistencia Privada, 1950: XIII). Otra función del Estado en la extinción de las instituciones consiste en procurar condiciones mínimas para la adecuada prestación de los servicios.

${ }^{23}$ Uno de los dilemas de la rendición de cuentas está en determinar si las instituciones asistenciales constituyen bienes públicos o bienes privados. Los bienes públicos resuelven problemas colectivos y su creación constituye un beneficio general. Desde esa perspectiva, la legislación mexicana las considera como servicios de interés público o bienes públicos financiados con recursos privados (Gudiño, 1999). Cabe notar que la discusión es más amplia y tiene que ver con la naturaleza de la propiedad de los bienes y con el carácter no lucrativo de las instituciones, temas que exceden la cobertura del análisis que aquí se realiza.

${ }^{24}$ Esos momentos, identificados por la Junta de Asistencia Privada (JAP) en 1950, continúan con vigencia en las funciones actuales de la JAP, por lo que se señalan aquí con algunas adecuaciones a las circunstancias contemporáneas. 


\section{El primer momento de la rendición de cuentas}

De modo muy amplio se puede decir que las instituciones operan con recursos provenientes de cuatro fuentes principales: a) los recursos privados constitutivos que tienen su origen en las aportaciones fundantes de la institución; $b$ ) los recursos privados que apoyan o sostienen la operación y que se entienden provenientes de donativos efectuados por otros agentes privados (algunos de los cuales son producto de exenciones fiscales); c) los recursos provenientes de subsidios y apoyos otorgados por el gobierno federal y los gobiernos locales, y $d$ ) las cuotas de recuperación que aportan los usuarios de la asistencia privada por servicios prestados. Cabe reiterar que la provisión de recursos financieros de las instituciones asistenciales es un punto crucial para asegurar el cumplimiento de los fines, la permanencia y la calidad de los servicios y prestaciones que se pueden brindar. El origen de sus capitales define el carácter privado y la forma de aplicación del carácter no lucrativo, así como la credibilidad en términos de transparencia y rendición de cuentas.

De acuerdo con lo que expresa la Ley de Instituciones de Asistencia Privada del Estado de México (2001): "Las instituciones de asistencia privada son personas morales con fines de interés público, que con bienes de propiedad particular ejecutan actos de asistencia social sin designar individualmente a los beneficiarios y sin propósito de lucro". En tal virtud, desde el momento de su constitución, las instituciones deben manifestar cuáles son los bienes y recursos privados que sustentarán el cumplimiento de su objeto social. En el caso de las fundaciones, los bienes constitutivos destinados son la base para integrar el patrimonio; es decir, se trata de fondos económicos destinados a fines determinados. En el caso de las asociaciones, se entienden financiadas por las aportaciones de los asociados. En ambos casos, a esas provisiones privadas se suman las aportaciones, donativos, herencias, legados, subsidios, productos y toda clase de ingresos que reciba la institución. Una condición esencial, prevista por la legislación, es que las instituciones no pueden redistribuir beneficios entre sus integrantes, condición que deriva de su carácter no lucrativo.

De conformidad con lo que las IAP mexiquenses declaran al momento de su constitución, su financiamiento, previsiblemente, será provisto por tres rubros principales: $a$ ) las aportaciones en dinero o bienes que realicen sus asociados o fundadores, así 
como las que en el futuro se establezcan para ser parte de la asociación o fundación; $b$ ) los donativos o legados que otorguen a la fundación o asociación, tanto sus integrantes como la sociedad en general, y los derechos que les fueren transmitidos, y $c$ ) los ingresos que se deriven de las actividades que realicen en cumplimiento de su objeto social.

El panorama que aporta la exploración de las instituciones de asistencia privada del Estado de México muestra la escasez de los fondos iniciales destinados a la asistencia. Los datos registrados en los estatutos constitutivos advierten que de las 171 instituciones que operaban en 2002, 129 (75.44\%) no registran bienes ni recursos financieros, mientras que sólo 31 instituciones (18.13\%) sí los registran y 11 instituciones más no proporcionan ninguna información al respecto. ${ }^{25}$ Es indispensable aclarar que la falta de registro de fondos económicos no implica indefectiblemente que éstos no existan; en cambio, la omisión sí deja establecido que sin su registro, los fondos legalmente inexistentes pueden ser destinados o no al objeto asistencial, lo que pone también en tela de duda su origen y su destino (gráfica I del Anexo).

Por su parte, la aproximación a los bienes y recursos de las 31 instituciones que los registraron, nos permite conocer que sólo cuatro instituciones $(2.3 \%)$ aportarían algún bien inmueble, casa o terreno; una institución registra aportación en bienes inmuebles y dinero $(.5 \%)$, cuatro registran sólo bienes muebles $(2.3 \%)$, una no registra el tipo de bienes, y las 24 instituciones restantes (13.4\%) se constituyen con base en aportaciones en dinero que van de 500 a 100 mil pesos. ${ }^{26} \mathrm{El}$ rango de aportación es el que a continuación se menciona (gráfica II):

- Cinco instituciones se registran con mil pesos o menos de capital inicial.

- Quince instituciones se registran con un capital inicial de entre 10 y 50 mil pesos.

- Cuatro instituciones se registran con un capital de entre 51 y 100 mil pesos.

${ }^{25}$ Para su registro ante la Junta de Asistencia Privada, las instituciones deben presentar el documento de su constitución formalizada ante Notario Público; en ese documento se declaran los bienes que constituyen el patrimonio inicial de la institución.

${ }^{26}$ La fuente de los datos son las solicitudes de registro ante la Junta de Asistencia Privada del Estado de México de las instituciones constituidas hasta noviembre de 2002 (Junta de Asistencia Privada del Estado de México, estatutos constitutivos, 2000-2002). 
La información registrada nos advierte sobre una debilidad económica estructural de las instituciones, ya que solamente en uno de los casos, los bienes registrados aseguran el funcionamiento y la posible calidad en las prestaciones de una institución asistencial. ${ }^{27}$ Asimismo, se infiere que las fundaciones, tal como están concebidas en los ordenamientos legales, son prácticamente inexistentes, en virtud de que ninguna institución inicia su operación con un patrimonio fundante que asegure su financiamiento. En esa apreciación se debe considerar que es a partir de la legislación de 2001 que en esta entidad federativa se prescribe un mínimo de 100 salarios mínimos vigentes para poder constituir una IAP con la modalidad de asociación, y de mil salarios mínimos vigentes en la zona geográfica de su constitución con la modalidad de fundación. ${ }^{28}$ De cualquier manera que se mire, los datos muestran que las instituciones no son sostenibles y carecen de un patrimonio que asegure la continuidad de sus acciones y el cumplimiento de sus objetivos.

Los datos referidos dejan ver que la debilidad financiera de las instituciones asistenciales constituye uno de los problemas más importantes para que las IAP puedan desempeñar un papel importante en la asistencia social, pues todo apunta a que, salvo algunas excepciones, los recursos privados que se destinan a ese campo pueden calificarse como pequeñas contribuciones individuales y no alcanzan a ser percibidos como el resultado de una verdadera cultura filantrópica. Tal vez de mayor relevancia es el hecho de que se reconozca y permita el funcionamiento a instituciones que claramente no tienen posibilidades de operar de manera adecuada por sus escasos recursos financieros, lo que hace patente el peso de las reglas informales que propician tales concesiones. Es en ese sentido que se considera que una vigilancia permisiva y laxa opera negativamente en la consolidación de las instituciones.

En lo que concierne a las aportaciones de otros donantes, los reportes de visita a las instituciones permiten estimar que los donativos proceden de empresas y personas; sin embargo, las do-

${ }^{27}$ La información se refiere a la institución de asistencia privada Misioneras y Misiones de la Encarnación IAP, la que declara poseer un inmueble y dinero por un valor total de 1'511,924.00 pesos.

${ }^{28}$ El Estado de México integra dos zonas distintas para la fijación del salario mínimo; en términos generales se estiman para el año de 2004 en cinco mil pesos la aportación mínima solicitada a las asociaciones, y en cincuenta mil pesos la de las fundaciones, cantidades muy menores para asegurar la sostenibilidad de las instituciones (Ley de Instituciones de Asistencia Privada del Estado de México, 2001, Artículo 25, fracción Iv). 
naciones no son elevadas y pocas instituciones aclaran su procedencia, además de que existe escasa información sobre su monto y empleo. ${ }^{29}$ Otro rubro importante son los apoyos de los gobiernos locales, que además de inmuebles o terrenos, aportan subsidios para financiamiento (gráfica III).

Las cuotas constituyen una importante fuente de ingresos para la asistencia privada en el Estado de México: más de la mitad del conjunto de las instituciones cobran cuotas de recuperación, si bien los montos no son elevados y oscilan entre $\$ 120.00 \mathrm{y}$ $\$ 3,000.00$ para servicios como cursos, guardería, educación especial, rehabilitación y albergue; mientras que las cuotas por servicio prestado -generalmente consultas, clases o sesiones de rehabilitación- van de $\$ 5.00$ a $\$ 80.00$.

Si se tiene en cuenta el tipo de servicios que prestan las instituciones: atender a ancianos en situación de abandono, cuidar de niños huérfanos y abandonados, rehabilitar a discapacitados, y brindar atención médica, servicios de educación especial y otros rubros socialmente necesarios, se puede apreciar que ofrecen servicios económicos y accesibles que los gobiernos en sus distintos ámbitos no tienen capacidad de proporcionar, por eso muchas veces éstos subsidian o trabajan en colaboración con las IAP. La información organizada en relación con el número de instituciones que cobran cuotas, muestra que éstas son la fuente principal del sostenimiento de $65 \%$ de las instituciones (gráfica IV).

El aspecto del financiamiento institucional que involucra el pago de los usuarios por servicios prestados puede marcar un ámbito distinto de la rendición de cuentas que actualmente no se encuentra considerado en la supervisión de las instituciones y que tiene que ver con ante quién o quiénes tiene que darse cuenta de los recursos utilizados y del desempeño institucional. ${ }^{30}$

En el caso de las IAP, cabe destacar la forma como este primer momento de la rendición de cuentas, como control ex ante, es determinante para sentar las bases de la estructura organizacio-

${ }^{29}$ Entre las empresas donantes se encuentran: Grupo Lala, Danone, Comex, Grupo Garcés, Aurrerá, Wal Mart, Caja y Empaque Modernos, Gasolinera Tecnológico, Banca Confía y la Fundación Kellogg. Otros donantes identificados con el gobierno y los agentes privados son el Nacional Monte de Piedad y la Lotería Nacional.

${ }^{30}$ Aun en el supuesto de que los usuarios de esos servicios fuesen considerados beneficiarios de las acciones no lucrativas, y no como clientes que pagan por un servicio, existirían aspectos del desempeño institucional que tendrían que formar parte de los procesos de rendición de cuentas. En ese rubro se incluyen las distinciones sobre la propiedad o pertenencia de las instituciones y la obtención de ganancias, las cuales, en el caso de las organizaciones lucrativas, son de apropiación legítima de los dueños o propietarios. 
nal de las instituciones, así como para orientar su acción conforme a normas y principios establecidos. Es pertinente advertir también que en ese momento está contenida de inicio la función coercitiva de la JAPEM, por medio de la autorización de la operación institucional. En ese sentido, las evidencias sobre los hechos de las autorizaciones otorgadas para el funcionamiento de las instituciones asistenciales privadas revelan: primero, una previsible escasa capacidad de respuesta a la obligación de brindar los servicios asistenciales que son la razón de ser de las instituciones, y, segundo, una limitada capacidad coercitiva del organismo de vigilancia. Ambas debilidades operan negativamente para el fortalecimiento institucional.

\section{El segundo momento de la rendición de cuentas}

Derivado de las prescripciones de la legislación y de las funciones propias de la Junta, uno de los propósitos sustantivos de las visitas de supervisión es verificar que las instituciones cumplan con su objeto asistencial; este rubro es, claramente, el de mayor relevancia para la vigilancia y para la orientación de la asistencia privada en la entidad. No obstante, las decisiones sobre si las instituciones cumplen o no cumplen con su objeto asistencial revisten alguna complejidad; las dificultades se derivan parcialmente de que los objetivos asistenciales declarados cuando se constituyen las instituciones son con frecuencia expresados en términos de misión, no precisándose con claridad el tipo de servicio, la población a atender y las dimensiones de la tarea, que muy raras veces se vincula con los recursos disponibles. De modo que determinar si las instituciones cumplen o no es una tarea para la que no existen parámetros, y que es ejercida discrecionalmente y con criterios variables.

Por otra parte, la medida del cumplimiento del objeto asistencial se percibe también limitada por la concepción de cumplimiento que tiene el organismo evaluador, puesto que la Junta la identifica prácticamente con una correspondencia entre la declaración constitutiva y la verificación de la población objetivo, y deja de lado la estimación del cumplimiento en términos de logro para los beneficiarios. Así, por ejemplo, no es posible saber por los reportes de supervisión cuántos fármaco-dependientes son rehabilitados, cuáles son los resultados de la educación especial que se imparte, cómo mejoran o se rehabilitan enfermos y 
discapacitados, o cuál es el impacto y seguimiento de la atención en los servicios de asistencia alimentaria.

A pesar de esas limitaciones, la estimación del cumplimiento de los objetivos sociales es un punto central de la rendición de cuentas de las IAP. Los datos de la supervisión indican que en el año 2000, 61\% de las instituciones sí cumplieron con su objeto asistencial, 15\% cumplió parcialmente, y se estimaría que 24\% enfrentó problemas para cumplir con su misión ${ }^{31}$ (gráfica v). En razón de esos indicadores, se estimó conveniente aproximarse al contenido de los informes y profundizar en la naturaleza de los problemas que enfrentan las instituciones para el logro de sus objetivos, para lo cual se revisaron los informes de las instituciones que cumplieron parcialmente y los de aquellas que fueron reportadas en situación de no cumplimiento.

En relación con el tipo de problemas que enfrentaron las instituciones para cumplir con sus objetivos, puede decirse que, con algunas variaciones, los más comunes consisten en que las personas que deciden fundar una institución y constituirse como patronos, no tienen los elementos para organizarse administrativamente y brindar el servicio; los rubros reportados, como deficiencias en la atención, falta de recursos, ausencia de documentación comprobatoria y desorganización del patronato, apuntan hacia ese tipo de problemas. Los problemas identificados, como población real difiere de población objetivo y población no significativa, nos advierten sobre instituciones muy débiles que no logran articular un servicio permanente. Por otra parte, la proporción de instituciones que registraron problemas diversos, y que oscila entre $18 \mathrm{y}$ $40 \%$, nos habla de condiciones institucionales precarias o al menos desiguales en la prestación de los servicios, en las que es todavía difícil, si no imposible, pensar en establecer criterios de calidad para determinar la cobertura, alcance e impacto del sistema institucional (cuadros 1 a 6 del Anexo).

La imagen de la asistencia privada que perfilan esos datos deja ver que las IAP enfrentan problemas para cumplir con su objeto social y que existen limitaciones en los esquemas de supervisión para medir su desempeño, porque el modelo de rendición de cuentas no considera indicadores sobre calidad de los servicios o cumplimiento de las normas técnicas, y tampoco alguna estimación del valor social que crean las acciones asistenciales. 
Por su parte, las instituciones que sí cumplen con su objeto social, también lo hacen en el contexto de una defectuosa rendición de cuentas. Son observaciones recurrentes en los registros de supervisión, el que las IAP no han rendido informes de labores y que no realizan sus asambleas de asociados. Debe advertirse que algunas instituciones recurren a los medios de comunicación: diarios locales, la radio o la televisión, para dar cuenta de acciones y eventos; sin embargo, son formas que quedan en el ámbito de la difusión ocasional de sus labores asistenciales y no de la rendición de cuentas. ${ }^{32}$

Otro de los rubros principales de la vigilancia del Estado está centrado en el cuidado del patrimonio de las IAP, y en la supervisión sobre el origen y el manejo de los fondos que se destinan al cumplimiento del objeto asistencial. El interés del Estado está dirigido a tres aspectos fundamentales: hacer cumplir la voluntad de los socios y fundadores, vigilar que no se lesione el interés público, y cuidar que no exista mal uso en las prerrogativas fiscales. La vigilancia que se ejerce sobre el empleo del patrimonio de la institución considera la autorización de presupuestos de ingresos y egresos, así como la revisión de estados contables y de inversiones, la propiedad de inmuebles y de condiciones de operación. Asimismo, entre las facultades de la Junta está acreditar a las instituciones ante la Secretaría de Hacienda y Crédito Público para que puedan ser autorizadas a recibir donativos deducibles de impuestos, lo que constituye una parte importante de los ingresos que sustentan las tareas asistenciales.

Por lo que toca al seguimiento de la rendición de cuentas, en el apartado anterior se habló sobre los fondos que las IAP declaran al constituirse y sobre la debilidad económica estructural de las instituciones por no asegurar su sostenibilidad. En este segundo momento se revisa a las instituciones ya en funcionamiento, lo que permite convalidar los datos de la etapa anterior. De la información recabada se infiere que los visitadores encuentran dificultades para que las instituciones informen sobre sus fondos y capitales; una observación frecuente de los reportes de inspección es que las instituciones no tienen en orden sus estados financieros y contables, y que éstos no son reportados con oportunidad a la Junta. Igualmente, entre las observaciones recurrentes

\footnotetext{
${ }^{32} \mathrm{La}$ aseveración se refiere a las IAP que constituyen el universo de estudio; sin embargo, existen en el país algunas instituciones asistenciales muy consolidadas que hacen pública rendición de cuentas, pero esos casos se pueden considerar la excepción y no la regla.
} 
derivadas de la supervisión se encuentra que las instituciones no cuentan con registros contables y que no cumplen con su declaración fiscal. ${ }^{33}$ Esas observaciones son significativas en el contexto de la rendición de cuentas porque dejan ver que existe poca claridad en los presupuestos del modelo: a quién rendir cuentas, sobre qué rendir cuentas y cómo hacerlo. ${ }^{34}$

De ese modo, no es posible saber con certeza si las IAP auditan sus estados financieros, se ignora si cumplen con sus declaraciones de impuestos, al parecer no elaboran presupuestos operativos ni realizan una planeación sustentada en la disponibilidad de sus recursos, y tampoco se encuentran elementos de información que justifiquen sus decisiones. En suma, no cuentan con los instrumentos ni aplican los criterios que les permitan efectuar la rendición de cuentas implícita en los servicios y prestaciones de interés público. En función de esas limitaciones, y a partir de la exploración que se ha realizado a la inspección del patrimonio institucional, existen elementos que son indicativos de que las instituciones se desempeñan menos bien de lo que sugiere la imagen que ellas mismas difunden entre la opinión pública, donde se presentan como instituciones comprometidas con el bienestar, poseedoras de principios altruistas y elevada moralidad.

\section{El tercer momento de la rendición de cuentas}

De conformidad con las prescripciones de la legislación vigente, es una atribución de la Junta de Asistencia Privada autorizar la extinción de las IAP. Dicha atribución tiene sustento en varias premisas jurídicas cuyo espíritu esencial es asegurar la rectoría del Estado, considerar a los beneficiarios como los titulares de los bienes y preservar el interés público. ${ }^{35}$ De ese modo, la ley respec-

${ }^{33}$ Una observación recurrente para las instituciones, en este rubro, es la siguiente: "Entregar estados financieros a partir de la fecha de inicio de sus operaciones, en cumplimiento del artículo $75^{\circ}$, párrafo 1 de la Ley de Instituciones de Asistencia Privada del estado de México. Entregar copia de R.F.C. Entregar presupuesto de ingresos, egresos e inversiones en activos fijos". Ejemplo tomado del Reporte de visita al Centro de Educación Especial y Rehabilitación Elvira Delgado de Almazán, IAP, número de acta de visita: 016/JAP/2002.

${ }^{34}$ La recurrencia se considera con base en el hecho de que 60\% de las instituciones visitadas por la JAPEM registra observaciones de faltas en su documentación financiera y contable; igualmente, $100 \%$ de las instituciones que recibieron recomendaciones para corregir su funcionamiento registra observaciones de manejo financiero.

${ }^{35}$ El sustento para marcar esa orientación a las facultades de la JAP para autorizar la extinción de las IAP se condensa en los Artículos $11^{\circ}, 96^{\circ}$ y $100^{\circ}$ de La Ley de Instituciones de Asistencia Privada del Estado de México, así como en los Artículos $5^{\circ}, 50^{\circ}$ y $51^{\circ}$ de la Ley de Asistencia Social, que advierten claramente que la rectoría de la asistencia corresponde al Estado y que ésta es un servicio de interés público, facultando 
tiva, en su Artículo $96^{\circ}$, considera que las instituciones pueden ser extinguidas de oficio o a solicitud de las mismas cuando:

- Sus bienes no sean suficientes para cumplir con su objetivo.

- Se constituyan con infracción a las disposiciones legales.

- Sus actividades pierdan el sentido asistencial que les dio origen.

- Obtengan una certificación negativa de la Junta.

En el caso de las instituciones que constituyen el universo de este estudio, la Junta autorizó entre 1993 y 2003 la extinción de 63 de las 171 instituciones que operaban hasta el año 2002;36 es decir, $36.84 \%$, dato que puede ser estimado como un indicador mayor de la debilidad de las instituciones. De acuerdo con el examen de las actas de extinción correspondientes a las instituciones canceladas, son causas frecuentes de las determinaciones de la JAPEM: a) que las instituciones no cumplieron con su objeto social, no se encontraban funcionando, no contaban con las condiciones de higiene y salubridad necesarias, o bien atendían a un número no significativo de beneficiarios; $b$ ) que presentaban deficiencias en la administración; es decir, irregularidades en el manejo de los recursos financieros, o carecían de recursos humanos y materiales para la adecuada prestación de los servicios, y c) en algunos casos, la extinción fue solicitada por las propias instituciones porque no contaban con los recursos necesarios para cumplir con su objeto. ${ }^{37}$

Las causas de la extinción de las instituciones se asocian con insuficiencias en los procesos de rendición de cuentas y pueden ser ubicadas en las variantes de accountability, particularmente las de accountability política, administrativa y financiera. La relación está determinada por los momentos ex ante y ex post, en los que la interacción entre las instituciones y la instancia coercitiva no propició el fortalecimiento de las instituciones y la corrección del rumbo. En ese sentido, la laxitud inicial de la autoridad y las insuficiencias ins-

la autorización de su funcionamiento y consecuentemente la de su extinción (Ley de Instituciones de Asistencia Privada del Estado de México, 2001; Ley de Asistencia Social, 2004).

${ }^{36}$ Estos datos incluyen las actas de extinción de las instituciones hasta el año 2003, porque en ellas se encuentran registradas las instituciones correspondientes a los reportes de supervisión de los años 2000-2002 que constituyen el referente para el estudio.

${ }^{37}$ Los Informes de visita reportan, asimismo, irregularidades en la posesión de los inmuebles, inexistencia de las instituciones o falta de la prestación de los servicios (JAPEM, Reportes de visita de inspección y actas de extinción 2000-2003). 
titucionales en la rendición de cuentas desembocaron en el debilitamiento y la extinción de las instituciones.

Las deficiencias en el ámbito de la accountability política están referidas en el proceso de extinción al incumplimiento de los objetivos asistenciales. La información recabada indica con claridad que las instituciones no cumplieron con sus objetivos, o que se trataba de instituciones fantasma, que no existían en los hechos, que no llevaban a cabo ninguna labor y que no tenían beneficiarios de sus acciones.

Las insuficiencias en el ámbito de la accountability administrativa son señaladas como ausencia de activos organizacionales, limitaciones de infraestructura, carencia de personal directivo $u$ operativo, y falta de recursos humanos especializados.

Particularmente, los procesos de extinción se refieren a insuficiencias en la rendición de cuentas sobre los recursos económicos y el financiamiento de las instituciones; advierten que las instituciones nunca pudieron contar con los recursos económicos y materiales que sustentaran su operación. En otras palabras, fueron extinguidas principalmente por la imposibilidad que tuvieron para sostener su operación o brindar los servicios. ${ }^{38}$

Cabe notar que, en el caso de las instituciones que aquí son estudiadas, se combinan y acumulan los distintos tipos de insuficiencia, lo que permite a la autoridad efectuar los juicios sumarios procedentes para declarar la extinción de las instituciones. Ochenta por ciento de las instituciones extinguidas cabe en ese espectro de sanción extrema impuesta por la autoridad, por motivos de incumplimiento de responsabilidades, mientras que el 20\% restante fueron extinguidas a solicitud de las propias instituciones; pero aún en esta variante, los motivos aducidos por las instituciones son las insuficiencias patrimoniales y la falta de activos económicos para desarrollar su labor. ${ }^{39}$

Las condiciones de insuficiencia en la operación de un gran número de instituciones han sido reconocidas públicamente por la JAPEM; en declaración a algunos medios de comunicación, la

${ }^{38}$ Muestra de esa condición son las declaraciones asentadas en las actas respecto de que las instituciones extinguidas no contaron nunca con inmueble propio, no tenían instalaciones, o bien no detentaban ningún tipo de bien o patrimonio (Actas de extinción y recomendaciones formuladas a las IAP en el periodo de estudio).

${ }^{39}$ No todos los casos de extinción se encuentran documentados mediante actas o recomendaciones a las instituciones. La interpretación se apoya en la revisión de 20 actas de extinción y 27 reportes de recomendaciones efectuadas por la Junta de Asistencia Privada en el periodo de estudio, correspondientes a $75 \%$ de las instituciones que fueron extinguidas. 
JAPEM informó que en 2003 se había cancelado el registro a 30 "supuestas casas de asistencia" y que se habían efectuado recomendaciones a $50 .^{40}$

Los problemas detectados en el funcionamiento de las IAP que fueron extinguidas y las irregularidades que presentan otras de las instituciones que continúan funcionando permiten apreciar que la permisividad en la regulación y la vigilancia laxa sobre su constitución y funcionamiento, pueden operar como un factor negativo para el fortalecimiento y la permanencia de las instituciones, puesto que las deficiencias y debilidades pasadas por alto conducen finalmente a la extinción. De igual modo, la información corrobora que cuando las instituciones no consiguen articular los fines con los medios, y cuando carecen de la infraestructura organizacional que asegure su sostenibilidad, tienen pocas probabilidades de alcanzar un desempeño suficiente y adecuado, menos aún de satisfacer las demandas sociales.

\section{Rendición de cuentas y debilidades institucionales}

El balance de la supervisión realizada por la Junta de Asistencia Privada en tres momentos de la rendición de cuentas revela insuficiencia e inconsistencia en el cumplimiento de las obligaciones que en ese rubro las leyes prescriben para las instituciones, obligaciones que se arraigan en la concepción de las prestaciones asistenciales como servicios de interés público.

El análisis realizado deja ver, además de los problemas de las instituciones, fallas notables en los procesos de monitoreo, supervisión y seguimiento de las acciones emprendidas, así como insuficiencias en el modelo que actualmente se utiliza para dar cuenta del desempeño y de los resultados institucionales. Los indicadores permiten, asimismo, inferir las repercusiones de tales insuficiencias al propiciar la emergencia y operación de instituciones débiles, cuya precariedad se traduce en imposibilidad para lograr los objetivos que justifican su existencia.

En ese sentido, cabe reflexionar que el espíritu de la rendición de cuentas es el de crear transparencia, y que los procesos de accountability, al demandar información y justificación sobre las decisiones asistenciales, pueden contribuir a la construcción de fortalezas y capacidades que conduzcan no sólo al mejora-

${ }^{40}$ Declaraciones de Alfonso Naveda Faure, secretario ejecutivo de la JAPEM, al periódico El Sol de Toluca, 15 de septiembre de 2003 y 19 de febrero de 2004. 
miento de los servicios y al mejor desempeño institucional, sino también a la autodisciplina.

El perfil trazado sobre la rendición de cuentas de las instituciones asistenciales revela la necesidad de plantear nuevas premisas que orienten el proceso y plantea el imperativo de construir nuevos modelos de accountability acordes con la naturaleza público-privada de los servicios que se prestan, así como de las formas propias de operar y de tomar decisiones; también hace perceptible la necesidad de considerar la combinación sui géneris que pueden presentar los recursos disponibles. En ese contexto puede insertarse la demanda actual de las instituciones por una mayor autonomía, la que implicaría la existencia de otras instancias independientes ante quién o quiénes rendir cuentas.

Por otra parte, la idea de accountability para este tipo de instituciones presupone la existencia de información imperfecta, originada en la opacidad que acompaña a lo privado en oposición a lo público. Desde esa óptica, las instituciones asistenciales consideradas como servicios de interés público tendrían que abrir su operación al escrutinio público. Es decir, que si quieren ser efectivas y ser percibidas como tales, la rendición de cuentas tiene que ser pública. La accountability confidencial que presumiblemente pueda darse al interior de las asambleas de asociados y de los patronatos, no justifica a las asociaciones asistenciales como prestadoras de servicios de interés público; entonces, su rendición de cuentas tendría que buscar otras esferas legítimas de reconocimiento público. Este principio de publicidad aplica no solamente a las instituciones que tienen la obligación de rendir cuentas, sino también a las entidades que toman cuentas.

En el cuadro siguiente se presentan algunas de las relaciones identificadas entre los procesos de rendición de cuentas y las debilidades de la organización institucional.

- Setenta y uno por ciento de las instituciones extinguidas en el Estado de México entre 1993 y 2002 tenía menos de seis años de operación. ${ }^{41}$

- Los reportes de supervisión de las instituciones consignan que éstas se constituyen con base en aportaciones que no aseguran flujos continuos de operación.

- Sesenta y cinco por ciento de las instituciones asistenciales cobra cuotas por los servicios que prestan.

41 Junta de Asistencia Privada del Estado de México, 1993-2003. 


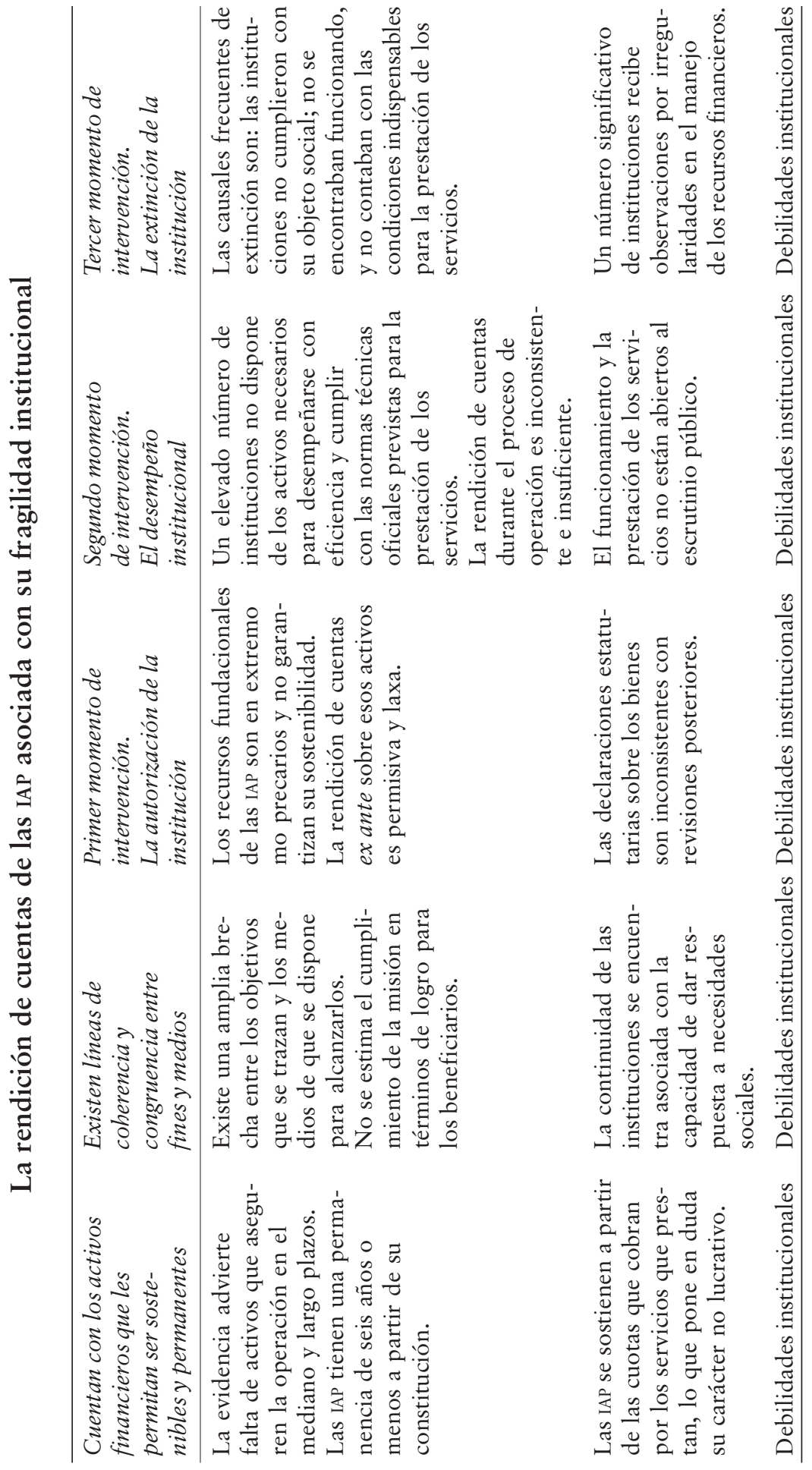


- Una de cada cuatro instituciones enfrenta severos problemas para cumplir con sus objetivos.

- Ciento veintinueve de las 171 instituciones que operaban en 2002, no declararon bienes al constituirse.

\section{Reflexiones finales}

No obstante desecharse la percepción común de que las instituciones privadas sean absolutamente transparentes, no puede dejarse a un lado que el problema crucial de las instituciones privadas estriba, actualmente, en su escasa capacidad de rendir cuentas de los recursos que manejan. Los rasgos de insolvencia de las IAP mexiquenses, que ya han sido expuestos, pueden ser una de las claves para la identificación positiva o negativa de las instituciones con los intereses y el bienestar común, y la base para un ejercicio en el que se pueda deslindar el confuso umbral del interés particular, meramente lucrativo y ausente de fines sociales.

La visión negativa sobre la opacidad en el manejo financiero de las instituciones puede matizarse si se tiene en cuenta que la supervisión sobre su patrimonio y sus recursos no puede ser interpretada como una transferencia de las responsabilidades gubernamentales relativas a la administración de recursos públicos (O’Connell, 1996). Las instituciones y las asociaciones civiles no son responsables ante la sociedad por los recursos públicos que les son administrados. Es responsabilidad del gobierno conocer a quiénes se otorgan recursos y por qué razones, y controlar el uso que se hace de ellos.

Otro de los aspectos negativos del conjunto de apreciaciones sobre la situación patrimonial de las IAP, es que las instituciones muestran una tendencia a basar su sostenibilidad y su desarrollo en una fácil disponibilidad de donativos, debilidad que se constituye en una amenaza permanente a la proyección de acciones consistentes y de largo plazo. En ese sentido, la permisividad de la intervención estatal y las insuficiencias del modelo de accountability operan como un factor negativo para el fortalecimiento de las instituciones.

La reflexión sobre la situación patrimonial de las instituciones asistenciales privadas conduce, asimismo, a considerar que las connotaciones de transparencia a las que aspiran esas instituciones implican un acceso público más extendido a la información sobre su operación, así como la obligación de hacer públicas las razones y explicaciones que justifican la aplicación de los 
recursos que les son donados, y sobre las decisiones que se toman en el desempeño de la institución. ${ }^{42}$

Para avanzar en esa dirección, el gobierno necesita reconocer la naturaleza dual de las organizaciones no lucrativas, como entidades económicas y sociales. En el modelo explorado, la rendición de cuentas ha sido estrechamente concebida y ha tendido a excluir los beneficios sociales, que son el fin último de la acción institucional.

Como puede notarse en esta aproximación a los procesos de accountability, las instituciones de asistencia privada enfrentan considerables dificultades para estructurar un modelo adecuado de rendición de cuentas. La adecuación del modelo requiere tomar en cuenta que el que actualmente se aplica no considera el valor que representan las contribuciones del trabajo voluntario ni los donativos en especie; tampoco se tienen mecanismos de registro estadístico de personas voluntarias y de horas de trabajo, y menos aún de los beneficios por cuidar ancianos, proteger niños abandonados o rehabilitar personas discapacitadas; en suma, no se recogen en el modelo los principios de una cultura filantrópica y estimativa de las aportaciones. Hace falta también propiciar la institucionalización de los procesos de rendición de cuentas, para lo cual es imperativo dejar de verlos únicamente como resultado de la acción coercitiva de las autoridades y, por el contrario, comenzar a percibirlos como mecanismos de autocontrol y disciplina generados por las propias instituciones. Tales inconsistencias no son privativas de México; se presentan también en países que cuentan con redes filantrópicas y asistenciales más extendidas.

Uno más de los aspectos fundamentales para avanzar en la transparencia consiste en incorporar la participación de los beneficiarios y la de los ciudadanos en general en la evaluación sobre la pertinencia y la calidad de los servicios, que es uno de los vacíos presentes hasta ahora en la rendición de cuentas. En ese sentido, es pertinente tomar en cuenta la advertencia de Michael Edwards y David Hulme sobre la existencia de un nivel en el cual la ausencia de accountability adopta el cariz de las acciones ineficientes e ilegítimas (Edwards y Hulme, 1996). Para lograr relevancia y legitimidad se necesita que las instituciones acepten ampliar la rendición de cuentas hacia unidades independientes, observadores, cuer-

${ }^{42}$ Aquí se alude a la publicidad como un concepto de exigencia tendente a que las acciones sean justificadas públicamente, a diferencia del concepto como esencia de lo público. 
pos académicos especializados y grupos sociales interesados; es igualmente indispensable que se incorporen al modelo de rendición de cuentas formas de auditoría social.

Una de las críticas a los modelos de rendición de cuentas para las organizaciones no lucrativas, es que no estiman el valor de lo que se crea. ${ }^{43}$ Así, en países como los Estados Unidos y Canadá se han empezado a aplicar métodos de auditoría social y de rendición de cuentas que incorporan formas flexibles para capturar el impacto social de las instituciones no lucrativas, al tiempo que buscan integrar una estimación del valor social de los servicios prestados por las instituciones. ${ }^{44}$

En la medida en que rindan cuentas, las instituciones pueden obtener mayor grado de autonomía y autoadministrarse, así como influir en la manera como deben acreditar su desempeño y en las mismas figuras ante quienes deben acreditarlo. En esa tesitura pueden también consolidarse y ganar mayor presencia y respeto como participantes en la búsqueda común por un mayor bienestar.

${ }^{43}$ Algunos estudios efectuados en otros países consideran que sería apropiado imputar un valor monetario al trabajo voluntario cuando el voluntario ocupa el lugar de un empleado remunerado (Mook et al., 2005; Quarter y Richmond, 2001).

${ }^{44}$ La práctica de auditoría social busca estimar el valor social de la labor institucional por medio de indicadores sociales y financieros. Richmond (1999) desarrolló un modelo combinado de contabilidad social con el propósito de contar con instrumentos de rendición de cuentas más adecuados al carácter no lucrativo y socialmente valiosos de las instituciones; entre los elementos relevantes del modelo se considera asignar un valor económico comparativo con los valores del mercado a los resultados institucionales. 
Anexo

Primer momento de la rendición de cuentas IAP

\section{Gráfica I}

Instituciones de asistencia privada en el Estado de México que al constituirse contaban con algún fondo económico

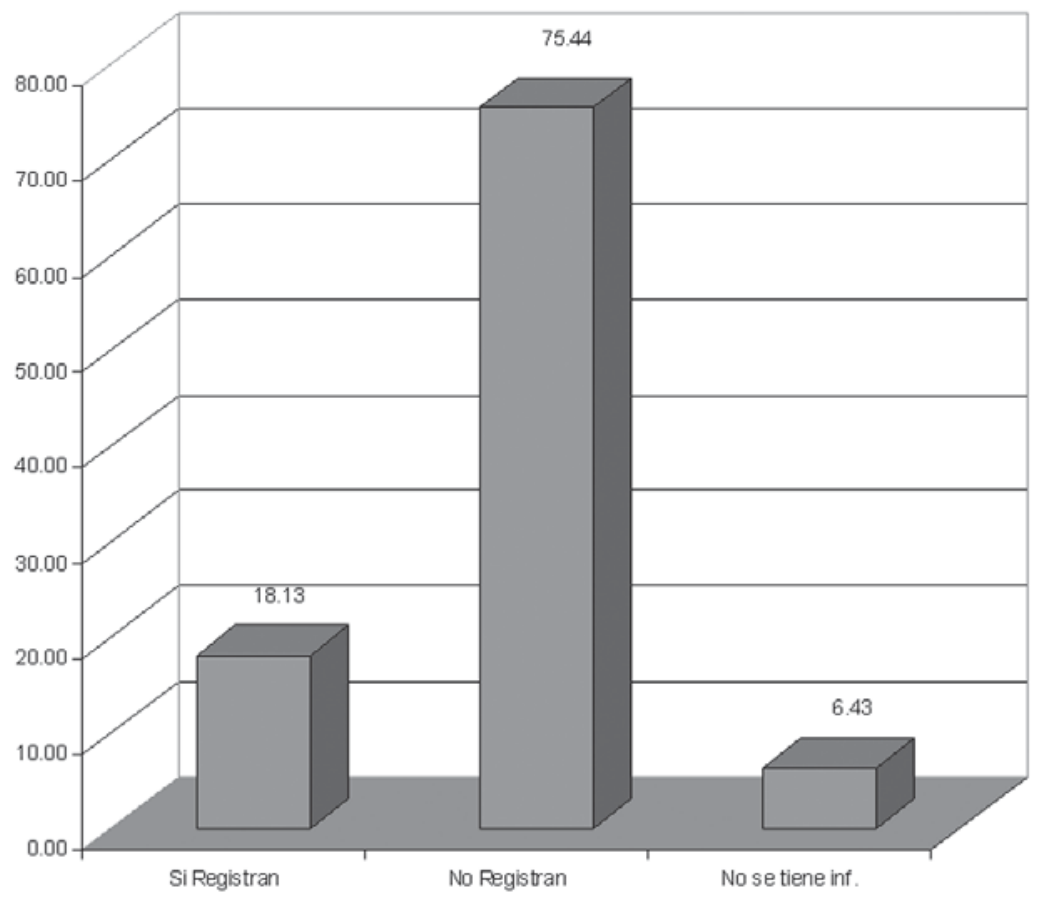

口PORCENTAJE

Fuente: Estatutos IAP. 
Gráfica II

Fondos que registran las instituciones al constituirse

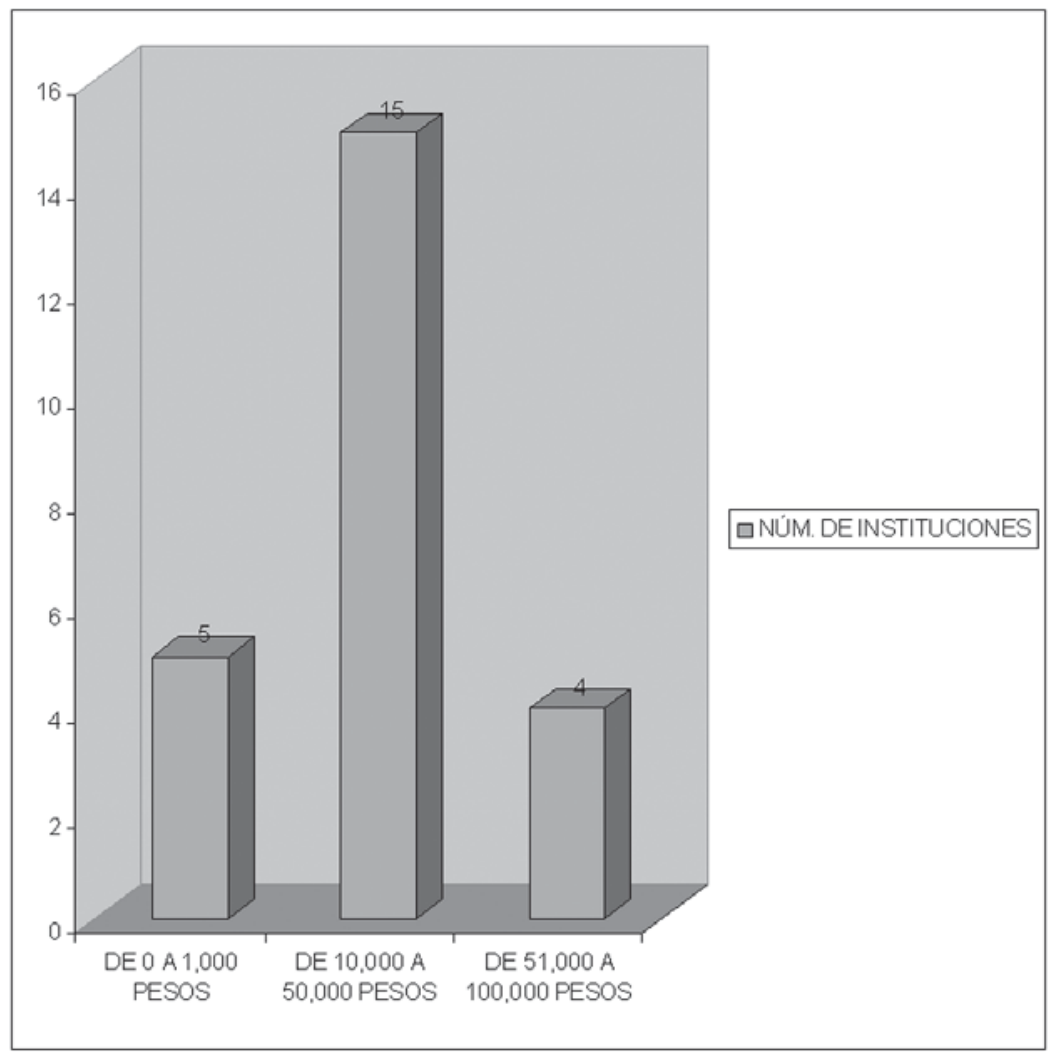

Fuente: Estatutos IAP. 
Gráfica III

Origen de apoyos y donativos de las instituciones de asistencia privada

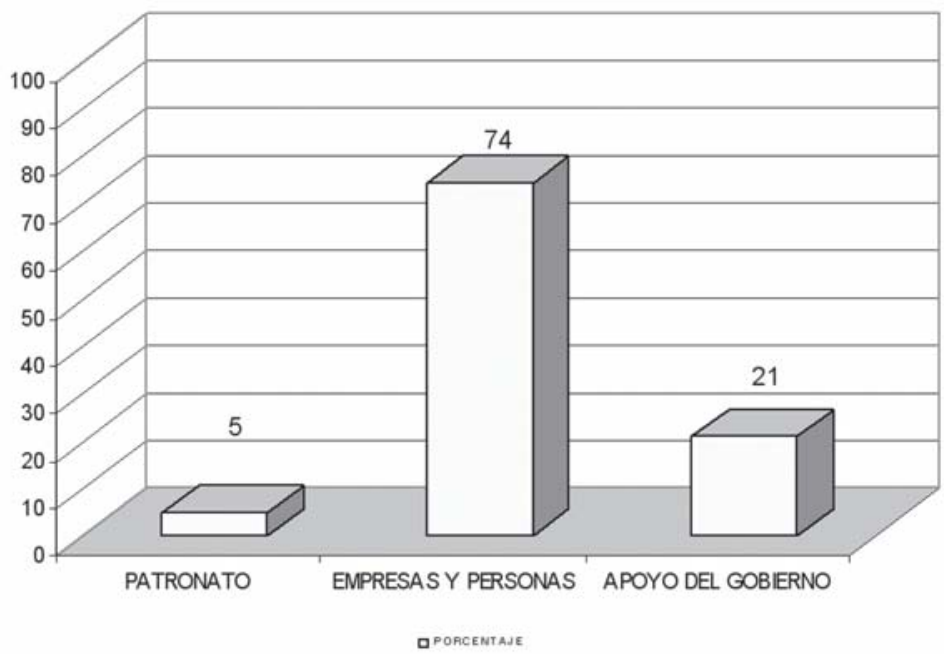

Instituciones que registraron dato sobre origen de apoyos y donativos: 65 . Fuente: Informes de visita, 2000-2002.

\section{Gráfica IV}

Existencia de cuotas en instituciones de asistencia privada

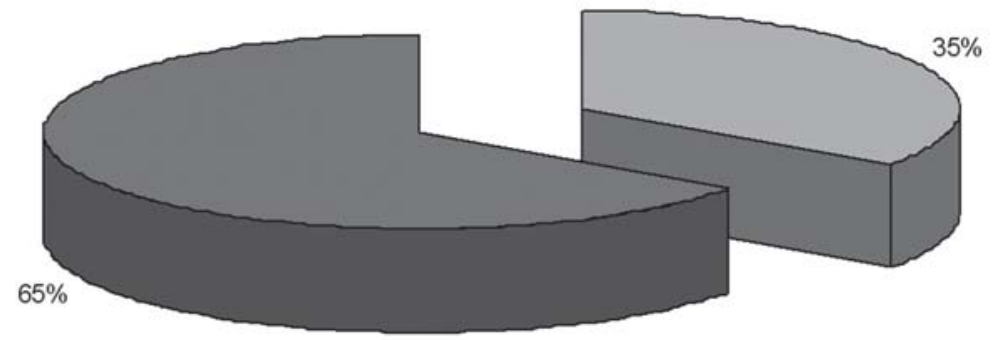

口NO EXISTEN

口SIEXISTEN

Fuente: Informes de visita, 2000-2002. 
Segundo momento de la rendición de cuentas IAP

Gráfica v

Condición de cumplimiento con el objetivo asistencial, año 2000

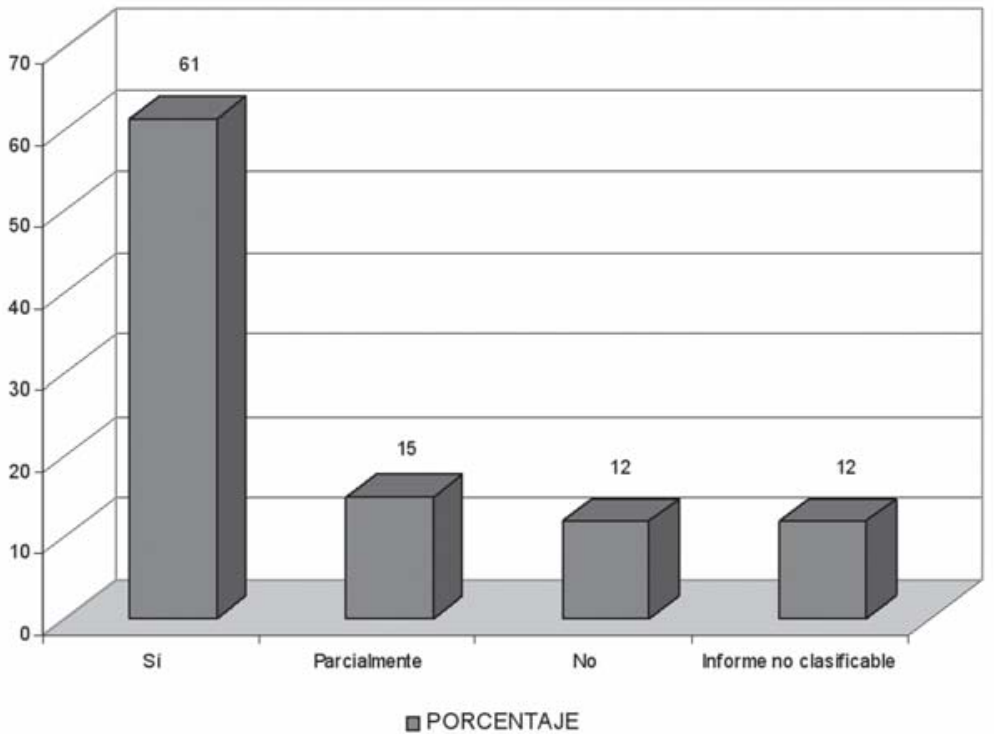

Informes de visita: 67.

Fuente: Informes de visita, 2000-2002.

\section{Cuadro 1}

Condición de cumplimiento del objeto asistencial, año 2000

\begin{tabular}{lcc}
\hline Condición de cumplimiento & Frecuencia & Porcentaje \\
\hline Sí cumple & 41 & 61 \\
Cumple parcialmente & 10 & 15 \\
No cumple & 8 & 12 \\
Informe no clasificable & 8 & 12 \\
Total & 67 & 100 \\
\hline
\end{tabular}

Total de instituciones año 2000: 140; instituciones visitadas: 67; instituciones que registran información: 67.

Fuente: Informes de visita, 2000-2002. 


\section{Cuadro 2 \\ Condición de cumplimiento del objeto asistencial, año 2001}

\begin{tabular}{lcc}
\hline Condición de cumplimiento & Frecuencia & Porcentaje \\
\hline Sí cumple & 33 & 61 \\
Cumple parcialmente & 11 & 20 \\
No cumple & 3 & 6 \\
Informe no clasificable & 7 & 13 \\
Total & 54 & 100 \\
\hline
\end{tabular}

Total de instituciones año 2001: 169; instituciones visitadas: 54; instituciones que registran información: 54 .

Fuente: Informes de visita, 2000-2002.

\section{Cuadro 3}

Condición de cumplimiento del objeto asistencial, año 2002

\begin{tabular}{lcc}
\hline Condición de cumplimiento & Frecuencia & Porcentaje \\
\hline Sí cumple & 63 & 66 \\
Cumple parcialmente & 5 & 5 \\
No cumple & 24 & 25 \\
Informe no clasificable & 4 & 4 \\
Total & 96 & 100 \\
\hline
\end{tabular}

Total de instituciones año 2002: 171; instituciones visitadas: 96; instituciones que registran información: 96.

Fuente: Informes de visita, 2000-2002.

\section{Cuadro 4}

\section{Problemas para el cumplimiento del objeto asistencial, año 2000}

\begin{tabular}{lcc}
\hline Tipo de problema & Frecuencia & Porcentaje \\
\hline Población real difiere de población objetivo & 3 & 14 \\
Falta de recursos & 1 & 5 \\
Deficiencias en atención & 4 & 19 \\
Desorganización del patronato & 8 & 38 \\
Abandono de labor asistencial & 1 & 5 \\
Ausencia de documentación comprobatoria & 4 & 19 \\
Total & 21 & 100 \\
\hline
\end{tabular}

Total de instituciones año 2000: 140; instituciones que fueron visitadas: 64; instituciones que registraron problemas: 18 .

Fuente: Informes de visita, 2000-2002. 


\section{Cuadro 5 \\ Problemas para el cumplimiento del objeto asistencial, año 2001}

\begin{tabular}{lcc}
\hline Tipo de problema & Frecuencia & Porcentaje \\
\hline Población real difiere de población objetivo & 3 & 9 \\
Falta de recursos & 7 & 20 \\
Deficiencias en atención & 12 & 34 \\
Desorganización del patronato & 8 & 23 \\
Actividad no significativa & 1 & 3 \\
Ausencia de documentación comprobatoria & 4 & 11 \\
Total & 35 & 100 \\
\hline
\end{tabular}

Total de instituciones año 2001: 169; instituciones que fueron visitadas: 54; instituciones que registraron problemas: 24 .

Fuente: Informes de visita, 2000-2002.

\section{Cuadro 6}

Problemas para el cumplimiento del objeto asistencial, año 2002

\begin{tabular}{lcc}
\hline Tipo de problema & Frecuencia & Porcentaje \\
\hline Población real difiere de población objetivo & 3 & 6 \\
Falta de recursos & 14 & 29 \\
Deficiencias en atención & 11 & 23 \\
Desorganización del patronato & 6 & 13 \\
Actividad no significativa & 2 & 4 \\
Abandono de labor asistencial & 4 & 8 \\
Ausencia de documentación comprobatoria & 8 & 17 \\
Total & 48 & 100 \\
\hline
\end{tabular}

Total de instituciones año 2002: 171; instituciones que fueron visitadas: 96; instituciones que registraron problemas: 48 .

Fuente: Informes de visita, 2000-2002. 


\section{Bibliografía}

Clark, John D. (2003), Worlds Apart. Civil Society and the Battle for Ethical Globalization, Kumarian Press Inc., Bloomfield.

Domínguez Orozco, Jaime y Cuauhtémoc Reséndiz Núñez (2001), Sociedades y asociaciones civiles: régimen jurídico fiscal, $11^{\mathrm{a}}$ ed., Ediciones Fiscales ISEF, México.

Edwards, Michael y David Hulme (1996), Beyond the Magic Bullet. NGO performance and Accountability in the Postcold War World, Kumarian Press, Nueva York.

Elster, Jon (1999), “Accountability in Athenian Politics”, en Adam Przeworski, Susan C. Stokes y Bernard Manin, Democracy, Accountability and Representation, Cambridge University Press, Cambridge, Reino Unido, pp. 253-278.

Ferejohn, John (1999), “Accountability and Authority: Toward a Theory of Political Accountability", en Adam Przeworski, Susan C. Stokes y Bernard Manin, Democracy, Accountability and Representation, Cambridge University Press, Cambridge, Reino Unido.

Guadarrama Sánchez, Gloria J. (2005), Ideas y fines de la asistencia privada en el Estado de México, 1986-2000, tesis doctoral, Universidad Nacional Autónoma de México.

Gudiño Pelayo, José de Jesús (1999), Las razones de mi voto II, Acción de Inconstitucionalidad 1/99: Ley de Instituciones de Asistencia Privada del Distrito Federal, Editora Laguna, México.

Hardin, Russell (2003), “Moralidad institucional”, en Robert E. Goodin (comp.), Teoría del diseño institucional, Gedisa, Barcelona, pp. 163-196.

Junta de Asistencia Privada (1950), La asistencia privada, tomo I, Editorial Ruta, México.

Martell, Michel S. (2005), La imputabilidad: un factor en la brecha moral entre el razonamiento y el potencial de ac- 
tualización del profesional, ponencia presentada en el v Seminario de Investigación sobre el Tercer Sector en México, Universidad Iberoamericana, octubre 2005.

Mook, Laurie et al. (2005), "Accounting for the Value of Volunteer Contributions", Nonprofit Management \& Leadership, Wiley Periodicals Inc., verano, 15 (4): 401-433.

O'Connell, Brian (1996), "A Major Transfer of Government Responsibility to Voluntary Organizations? Proceed with Caution”, Public Administration Review, mayo-junio, 56 (3): 222-225.

Quarter, Jack y Betty Jane Richmond (2001), "Accounting for Social Value in Nonprofits and For-profits", Nonprofit Management \& Leadership, otoño, 12 (1): 75-85.

Reygadas y Robles Gil, Rafael (1998), Abriendo veredas. Iniciativas públicas y sociales de las redes de organizaciones sociales, Convergencia de Organismos Civiles por la Democracia, México.

Richmond, Betty Jane (1999), Counting on Each Other: A Social Audit Model to assess the Impact of Non Profit Organizations, tesis doctoral dissertation, University of Toronto.

Schedler, Andreas (1999), "Conceptualizing accountability", en Andreas Shedler, Larry Diamond y Marc F. Plattner (eds.), The Self Restraining State: Power and Accountability in New Democracies, Lynne Rienner Publishers, Inc., Boulder, Colorado, pp. 13-27.

\section{Documentos}

Ley de Beneficencia Privada para el Distrito Federal y Territorios (1899), Diario Oficial del Supremo Gobierno de los Estados Unidos Mexicanos, 7 de noviembre.

Ley de Beneficencia Privada para el Distrito y Territorios Federales (1904), Diario Oficial de los Estados Unidos Mexicanos, 24 de agosto. 
Ley de Beneficencia Privada para el Distrito y Territorios Federales (1933), Diario Oficial del Gobierno Constitucional de los Estados Unidos Mexicanos, 31 de mayo.

Ley de Instituciones de Asistencia Privada del Estado de México (2001), LIv Legislatura del Congreso del Estado de México, Decreto núm. 26, 12 de junio.

Ley de Asistencia Social (2004), Diario Oficial de la Federación, 2 de septiembre.

El Sol de Toluca (2004), declaraciones del licenciado Alfonso Naveda, secretario ejecutivo de la Junta de Asistencia Privada, 19 de febrero.

Recibido: 28 de noviembre de 2005. Aceptado: 21 de febrero de 2006.

Gloria Guadarrama Sánchez. Licenciada en psicología por la Universidad Nacional Autónoma de México; maestra en sociología por la Universidad Iberoamericana y doctora en ciencias políticas y sociales por la UNAM; cuenta con estudios de especialización en tecnología educativa, de la Organización de Estados Americanos (OEA); en métodos de investigación educativa por la UNAM, y es diplomada en estudios de población y desarrollo por la Universidad Autónoma del Estado de México.

Actualmente es profesora-investigadora en El Colegio Mexiquense, institución en la cual también se ha desempeñado como coordinadora de investigación académica; sus líneas de investigación son la educación y las políticas sociales, especialmente las políticas de asistencia social.

Entre sus publicaciones recientes se cuentan: "Historia de la asistencia privada", en Sofía Zertuche y Tania Carreño King (eds), Historias de vocación y compromiso: la asistencia privada en México, México, Nacional Monte de Piedad-Marca de Agua Ediciones, 2005; "El bienestar de la población mexiquense y los sistemas de protección social”, en Pablo Mejia Reyes (coord.), La economía del Estado de México; hacia una agenda de investigación, Zinacantepec, Estado de México, El Colegio Mexiquense, A.C., 2004, y "Gerencia pública y política social en Latinoaméri- 
ca”, Economía, Sociedad y Territorio, vol. Iv, núm. 13, enero-junio de 2003, pp. 127-160.

Su libro titulado Entre la Caridad y el Derecho: Un estudio sobre el agotamiento del modelo nacional de asistencia social, editado por El Colegio Mexiquense y por el Consejo Estatal de Población (Coespo) en 2001, hace un examen profundo de la asistencia social en nuestro país, y particularmente en el Estado de México. 